\title{
Kaplan, David M. (ed.) 2012, Philosophy of Food, University of California Press, Berkeley, Los Angeles, London
}

\author{
Recensão de José Eduardo Reis \\ ILCML / Universidade Trás-os-Montes e Alto Douro
}

Os dezasseis ensaios de diferentes autores especializados em diferentes temáticas relacionadas com a alimentação humana e que integram o volume Philosophy of Food, publicado em 2012 pela University of California Press, são precedidos por uma introdução do seu editor, David M. Kaplan, que, de modo esclarecedor e sintético, disserta sobre diferentes domínios do discurso filosófico em torno da problemática do alimento. Atribuir ao tema da alimentação humana uma dignidade filosófica é reconhecer que a sua abordagem não é simples, que não se contém em estudos de caso ou se circunscreve ao campo exclusivo da teoria ética. Tal como ocorreu com a abordagem analítica de domínios da vida biológica, como por exemplo com o extenso e diversificado mundo animal não humano, ou com áreas da vida psicossocial, como por exemplo com a dignidade ontológica e o estatuto legal das minorias étnicas ou do género sexual, a temática do alimento não se constituiu num objeto recorrente ou especializado da reflexão filosófica. 0 que não significa que, ao longo da história do pensamento ocidental, a alimentação não tenha sido abordada de forma esparsa e segundo focalizações específicas: assim sucedeu com a proposta de definição da dieta ideal por Platão no livro II da República, ou com aspetos relacionados com a sua produção e o seu consumo por pensadores de diferentes eras, os estoicos, 
Epicuro e Séneca, os iluministas Locke, Rousseau e Voltaire, e os modernos Marx e Nietzsche. Segundo Kaplan, as dificuldades do estudo filosófico do alimento devem-se em parte à indefinida determinação do próprio objeto sobre que reflete, à sua difusa localização epistémica, à sua múltipla inscrição em áreas relativamente autónomas, como as da ecologia, da economia e da cultura. A dificuldade de fixação do objeto de estudo do alimento está na origem de múltiplos estudos empíricos parcelares, mas tem inibido a possibilidade de se pensar, de modo integrado e relacional, a natureza das suas qualidades essenciais. Os filósofos contemporâneos têm-se assim ocupado de temas tão variados como o direito à alimentação, a biotecnologia, o vegetarianismo, a ética agrária, a estética do paladar, o impacto da globalização na produção alimentar, a responsabilidade cívica e moral dos produtores e consumidores - temas que configuram alguns dos enfoques dos ensaios do livro em apreço. Na tentativa de definir um campo de investigação teórico não permeável à contingência dos factos e à proliferação conceptual sobre o tema da alimentação, Kaplan propõe que a função ordenadora e clarificadora do pensamento filosófico se estabeleça a partir da resposta a cinco perguntas nucleares: em que é que consiste exatamente o alimento?, o que é que pode ser comido?, como se sabe que aquilo que se come é seguro?, como se distribui o alimento?, o que é o bom alimento? Estas questões, aparentemente simples, têm porém um alcance metafísico, epistemológico, ético, político e estético, isto é mobilizam os principais domínios de reflexão do pensamento filosófico. É assim que, de modo sinteticamente didático, Kaplan discorre no seu ensaio introdutório sobre o fenómeno da alimentação na perspetiva de cada um desses domínios, designando-os sucessivamente por metafísica do alimento, epistemologia do alimento, estética do alimento, ética e tecnologia do alimento e política do alimento. Assim, à questão do que é o alimento, faz corresponder uma inquirição de tipo metafísico sobre a sua natureza e as suas propriedades. Essa inquirição não surge, porém, determinada univocamente, variando entre considerá-lo, respetivamente, como equivalente da nutrição, como uma emanação da natureza, como produto cultural, como um bem social, como um bem espiritual, como um desiderato geral, como um objeto estético, etc.

Ao questionamento metafísico do ser alimento, associa-se o modo epistemológico de 
como esse ser alimento é conhecido e justificado, percecionado e avaliado enquanto objeto de produção e consumo. Conforme os contextos, a epistemologia do alimento pode considerá-lo quer como objeto de apreciação gustativa, quer como portador de significado simbólico, pode tomá-lo como um fator indutor de doenças, envolvendo o risco e a necessidade de o evitar mediante o estabelecimento de normas de segurança nutricional, ou como um fator indutor de confiança na sua ingestão e partilha; pode também, do ponto de vista da razão prática, considerar o modo como ele é confecionado mediante receitas culinárias conhecidas por dado um grupo étnico, classe social ou profissional - que, em geral, lhe procura atribuir sentido. A epistemologia do alimento pode procurar ainda explicar distorções percetivas que podem ter a sua origem na fisiologia ou no inconsciente psicológico e refletir sobre as desordens alimentares como a bulimia, a anorexia, a compulsão.

A estética, enquanto domínio da filosofia configurada por juízos de gosto, articula-se também com a alimentação humana. Explorando o significado ambivalente do termo inglês, "taste", Kaplan faz notar a sua dupla aceção de designar o sentido físico mais diretamente envolvido na degustação do alimento, mas também de operar como a metáfora dominante da estética para referir os padrões de conhecimento utilizados nos juízos artísticos. Esta curiosa homografia do termo "taste", designando quer uma experiência sensorial quer um juízo de apreciação crítica, parece indiciar que, em ambas as possibilidades semânticas, é produtiva a tensão, embora de difícil resolução, entre a apreensão subjetiva/pessoal e a sua enunciação objetiva/universal. Se a experiência gustativa de um alimento é um fenómeno estritamente subjetivo, que pode ser aferido por critérios objetivos, já a produção de um juízo de gosto, não podendo deixar de tomar em conta a esfera subjetiva de quem o emite, terá, para ser devidamente qualificado, de se formular a partir de padrões objetiváveis de conhecimento estético. Essa tensão, segundo Kaplan, não deixa de estar presente num juízo de apreciação gustativo, o que implica reconhecer que nele participa uma dimensão cognitiva e simbólica: pelo alimento se expressa a cultura a que pertence (cozido à portuguesa, spaghetti italiano, sushi japonês), se materializa uma função cerimonial (eucaristia, pão ázimo), se processa um consumo alimentar que se tornou ritualizado em 
função das circunstâncias sociais (brindar com vinho e não com coca-cola). É ainda essa tensão que permeia o debate sobre o estatuto artístico atribuído às práticas culinárias e às técnicas gastronómicas.

Tal como sucede com os outros domínios do pensamento filosófico, a intersecção da ética com a alimentação processa-se num quadro de referências teóricas e de temáticas que, neste eixo de reflexão, se articulam em torno de quatro subdomínios. No primeiro deles, centrado na problemática da obrigação e da responsabilidade, Kaplan recorre à teoria de Kant sobre o dever a fim de realçar o imperativo moral que se coloca quer ao eu próprio quer ao outro para assegurar o pleno desenvolvimento de si e providenciar a doação, em condições seguras e regulares, do alimento a quem dele necessita. A noção do dever alimentar é sobretudo geradora de perguntas morais como as de saber qual o número de pessoas por que se é responsável alimentar, com que sacrifício individual isso deve ser feito, que tipo e qual a quantidade de alimento se deve providenciar, etc. 0 segundo subdomínio da ética do alimento referido por Kaplan é o que ele identifica sob a designação de virtudes alimentares. Partindo do postulado de que a virtude não é mais definível por princípios ou regras morais, mas por disposições de carácter - isto é, de que à questão do imperativo moral "o que devo fazer?" sobrevém a questão da virtude moral "em que pessoa aspiro tornar-me" -, o autor destaca as três principais virtudes alimentares que têm ocupado a reflexão filosófica: hospitalidade, temperança e modos de comer à mesa. 0 terceiro e quarto subdomínios dizem respeito à consciencialização moral da proveniência do alimento, aos desafios e limites colocados à hegemonia antropocêntrica sobre a natureza animal não humana e sobre o meio ambiente. Neste sentido, quer o vegetarianismo de base ética - baseado ou no reconhecimento de direitos intrínsecos conferidos aos animais (teoria deontológica) ou no interesse destes em se auto-preservarem (teoria utilitarista) -, quer a prática da agricultura ecologicamente responsável e da preservação de condições ambientais sustentáveis são tidas como aspetos determinantes da ética alimentar.

Todo o alimento humanamente comestível, seja ele de origem vegetal ou animal, utiliza diferentes estádios de processamento tecnológico que precedem o ato de comer, isto é, requer o uso de técnicas de produção ou de confeção que variam das mais simples 
(plantar, pastorear, cozinhar, secar, fermentar, etc.) às mais complexas (fertilizar, pasteurizar, congelar, aromatizar, etc.). As questões filosóficas associadas à tecnologia alimentar com implicação nos planos da ética, dos direitos dos consumidores, dos animais e da própria determinação metafísica da natureza do alimento, compreendem, segundo Kaplan, três formas de produção e sustento nutricional: os alimentos geneticamente modificados (plantas e animais cujo DNA foi recombinado com vista a aumentar o seu potencial orgânico), a biotecnologia animal (gado e peixes laboratorialmente redesenhados para se tornarem mais resistentes e se reproduzirem em escala industrial), e os alimentos funcionais (concebidos com fins regeneradores e terapêuticos).

Praticamente todos estes tópicos, temas e questões sobre o alimento têm implicações e ressonâncias políticas. A produção, distribuição e o consumo, os três vetores que configuram os sistemas nacionais e internacionais alimentares, e os seus subsumidos e multivariados aspetos, suscitam abordagens filosóficas divergentes convertidas doutrinariamente em posições de crítica ou de defesa política e económica sobre os seus respetivos procedimentos. A política alimentar, segundo Kaplan, agregando as questões previamente abordadas, distende-se com relevante pertinência a três outras temáticas: à segurança alimentar, à comercialização dos bens comestíveis e à sua rotulagem. Estas temáticas desafiam o pensamento filosófico a discorrer sobre (i) a mitigação e erradicação da fome e da subnutrição, (ii) os deveres dos governos mundiais em assegurar os meios de vida das populações de maneira a lhes garantirem o acesso a uma alimentação nutritiva e necessária à sua saudável preservação vital, (iii) as dinâmicas comerciais dos produtos alimentares associadas ao fenómeno económico da globalização, dos seus efeitos negativos nas economias agrárias dos países menos desenvolvidos e da consequente liquidação das dietas locais, (iv) as garantias baseadas em informação fiável e controlada de maneira a que o consumidor possa fazer livres e conscientes escolhas sobre a qualidade dos bens alimentares que adquire.

Os ensaios dos dezasseis autores de Philosophy of Food, representando diferentes tradições do pensamento filosófico - anglo-americano, europeu continental, pragmatista, feminista, e combinações múltiplas destas vertentes teóricas -, retomam, problematizam, 
ampliam e concretizam aspetos vários destas diferentes áreas da filosofia aplicadas ao tema da alimentação, tal como sinteticamente foram expostos por Kaplan. Assim, os dois primeiros textos abordam o papel social da alimentação. Roger Scruton, em "Real Men Have Manners", realça a importância das boas maneiras à mesa e a necessidade de elas serem preservadas e cultivadas enquanto índice de urbanidade e de demonstração prática das virtudes da cortesia, do decoro e da sã convivência inter-humana. Lisa Hedke, pela justaposição de termos que compõem o título do seu ensaio, "Down-Home Global Cooking”, sustenta a necessidade, a partir de um exame crítico dos fundamentos dos termos opostos "global" e "local", de se superar a conceptualização dos sistemas alimentares decorrentes da dicotomia socio-política que opõe cosmopolitismo e localismo.

A reflexão estética sobre o alimento ocupa os três textos subsequentes. "Hunger is the Best Sauce", de Kevin Sweeney, recorre aos contributos de dois pensadores franceses do século XIX, Grimod de la Reynière e Brillat-Savarin, para conceptualizar a noção de "gustatory imagination" e, por essa via, equiparar o prazer comedido e consciente da ingestão de alimentos à experiência de conhecimento estético conceptualizada por Kant. "Smells, Tastes and Everyday Aesthetics", de Emily Brandy, derrogando igualmente o esquema binário e dicotómico da apreensão comum da realidade sensível, dá continuidade ao argumento de Sweeney e dilui a oposição clássica, também estabelecida por Kant, entre os sentidos físicos superiores, da visão e audição, envolvidos na contemplação estética, e os inferiores, do olfato e do paladar, adequados à fruição sensível, porém tidos como privados de valor cognitivo. Com esta sua proposta, Brandy visa incluir no domínio da estética a experiência gustativa e aromática do ato alimentar. Carolyn Korsmeyer, em "Ethical Gourmandism", recorrendo ao conceito de "crítica ética", conceito que associa as qualidades morais de uma obra de arte ao seu valor estético, aplica-o ao tema do alimento e reconhece a dificuldade de se dissociar o prazer qualificado da experiência gastronómica do sentido de justiça e de adequação ética da sua origem e do seu conteúdo. 0 prazer do alimento ingerido não pode ignorar valores éticos relativos à sua proveniência e confeção. Este ensaio estabelece a ponte com os três que se seguem, de teor explicitamente moral e político, que examinam, de um ponto de vista normativo, um conjunto de tópicos sobre comida e política 
alimentar. "Two Evils in Food Country: Hunger and Lack of Representation", de Michel Korthals, identifica e analisa dois dos males alimentares do mundo contemporâneo, o da fome, como efeito da má distribuição dos recursos disponíveis para satisfazer as necessidades nutricionais de uma elevada percentagem da humanidade, e o da ausência de reconhecimento de diferentes estilos de comida associados a diferentes estilos de vida, a diferentes culturas, o que gera modos hegemónicos de consumo alimentar. Num quadrosíntese, o autor inventaria no final do seu texto as características destes dois males, que não são substanciais, mas social e ideologicamente estruturados, assim como os modos de com eles se lidar politicamente. Gary Comstock, em "Ethics and Genetically Modified Food", partindo de uma descrição dos valores epistemológicos e pessoais que sustêm a responsabilidade moral dos cientistas, propõe um método baseado em questões éticas de maneira a examinar a eticidade da tecnologia genética aplicada a modos de produção agrícola. Conclui polemicamente o seu ensaio afirmando que, com as devidas precauções, três teorias éticas, a dos direitos, a utilitária e das virtudes, convergem em aceitar que a produção de alimentos geneticamente modificados é eticamente aceitável. Em "The Ethics of Food Safety in the Twenty-First Century", Jeffery Burkhardt, recorrendo a dados e fontes de organizações internacionais e norte americanas, articula o seu ensaio a partir de quatro instâncias argumentativas: (i) definindo previamente a noção genérica de segurança alimentar, (ii) procedendo a um exame das responsabilidades éticas dos meios institucionais envolvidos na implementação dessa segurança, (iii) avaliando as práticas políticas que visam a implementação desse objetivo, (iv) fazendo uma revisão crítica da proposta de reestruturação do sistema de segurança alimentar que tome em linha de conta os seguintes fatores: a concentração agrícola e os seus métodos de produção industrial, a globalização dos mercados alimentares, as ameaças do bioterrorismo.

O conjunto dos três ensaios subsequentes têm como denominador comum a questão do vegetarianismo determinado por posições éticas relacionadas com a utilização de proteína animal na produção e consumo alimentares. Em "The Myth of Happy Meat", Richard Haynes desacredita a tese dos assistencialistas (welfarists) de considerarem o bemestar dos animais de criação como condição eticamente legitimadora da utilização final do 
seu corpo para fins alimentares. A errónea conceptualização assistencialista da ideia de bem-estar dos animais, criticada pelos defensores dos direitos dos animais (liberationists), estaria na origem do mito de que o corpo abatido de um animal criado em condições favoráveis ao seu desenvolvimento anularia o mal ético da sua morte para fins alimentares. "The Problem of 'Happy Meat' and the Importance of Vegan Education", da autoria de Gary Francione, desenvolve uma tese idêntica de crítica ao assistencialismo (welfarism), sustentando que os humanos não têm nenhuma justificação moral para usarem instrumentalmente os animais não humanos, sobretudo como fonte alimentar, por mais benévolo que seja o tratamento que lhes seja dado. É nesse sentido que o veganismo - a atitude eticamente fundamentada que rejeita o consumo de todos os produtos de origem animal - e a sua difusão pedagógica é, para este autor, a única posição ética consistente com o reconhecimento dos direitos dos animais. 0 ensaio de David Fraser, "Animal Ethics and Food Production in the Twenty-First Century", não ignorando em absoluto as linhas de argumentação dos textos anteriores, procura integrar no seu campo de reflexão ética parâmetros de análise convergentes com a conceção assistencialista (welfarist) do consumo da proteína animal. Nesse sentido, e, sem rejeitar a evidência empírica dos danos causados à integridade física dos animais e dos impactos negativos no meio ambiente provocados pela indústria agroalimentar, este autor rejeita o conteúdo da tese especista - que eticamente reconhece a injustiça da exploração e segregação levadas a cabo pela espécie humana das espécies animais não-humanas - por nela não descortinar um princípio de solução para o problema alimentar associado ao exponencial crescimento da população mundial no século XXI.

Na organização predominantemente triádica dos temas que integram The Philosophy of Food, seguem-se três ensaios que lidam com aspetos relacionados com a produção alimentar. Assim, Paul Thompson, em "Nature Politics and the Philosophy of Agriculture", discorre sobre as diferenças teóricas da filosofia agrária e da filosofia industrial da agricultura, das suas correspondentes fundamentações sobre a organização dos sistemas alimentares, bem como sobre o impacto das práticas agrícolas no meio ambiente e na sociedade. Por recurso a vários filósofos americanos e também por referência ao 
pensamento político e poético da antiga Grécia, o autor não só procura explicar a agricultura como uma potenciação, por vezes com prejuízos e abusos, dos recursos da natureza, mas também como uma atividade modelar e determinante do processo de formação da civilização humana: entre outros efeitos benéficos, os ritmos repetitivos das práticas de produção e consumo de bens agrícolas (sementeira, germinação, colheita) teriam servido, segundo este autor, de fundamento às filosofias morais orientadas para a definição das virtudes e do carácter moral individual e comunitário.

Os ensaios, respetivamente de Matthias Kaiser, "The Ethics and Sustainability of Aquaculture", e de David Castle, Keith Culver, William Hannah, "Scenarios for Food Security" procuram, de modo diferenciado - o primeiro por via da aplicação de uma matriz ética, o segundo por via da construção de cenários prospetivos sobre segurança alimentar fundamentar o recurso, devidamente controlado, à aquacultura, isto é, à produção de organismos aquáticos, peixes, moluscos, crustáceos e plantas aquáticas, como forma de responder quer às necessidades alimentares de uma população em crescimento exponencial, quer a possíveis cenários de crise ecológica.

Os dois últimos ensaios incidem sobre tecnologia alimentar. Gyorgy Scrinis, em "Nutritionism and Functional Foods," procede a um exame crítico e diacrónico dos estádios constituintes do que ele designa por ideologia nutricionista, uma conceção cientificamente redutora e amplamente difundida pela indústria alimentar com vista a promover o que é considerado, por critérios fluidos e conjunturais, o saudável, bom alimento. Este surge normalmente caracterizado por efeito de uma seletiva e parcial hipervalorização das suas propriedades bioquímicas e não pela correlação de fatores que determinam a sua relativa qualidade. Em alternativa a esta ideologia contemporaneamente legitimadora dos designados alimentos funcionais - produtos laboratorialmente concebidos para atender a necessidades dietéticas específicas - o autor propõe que, nos processos de representação dos sistemas alimentares, se considere a elaboração de um paradigma de aferição da qualidade tecnológica alimentar que integre todas as categorias de alimentos, mecânica, química, laboratorial e nano-processados. Por fim, Stellan Welin, Julie Gold, e Johanna Berlin, num registo utópico-prospetivo, procuram avaliar, no ensaio "In Vitro Meat," quais 
os aspetos morais em jogo associadas à possível produção biotecnológica, em laboratório, de proteína animal para fins alimentares. Reconhecendo que a crescente produção industrial de carne e sua utilização na dieta humana constituem um problema com implicações ecológicas e éticas que não pode ser ignorado, os autores divisam a possibilidade de se desenvolver, a partir dos progressos da engenharia genética, a tecnologia in vitro adequada, por recurso a bio-reatores, capaz de produzir a matéria comestível que, até ao presente, só se obteve pela caça e pelo abate industrializado de animais. Dando por adquirido essa possibilidade tecnológica, o ensaio conclui inventariando um conjunto de questões ético-filosóficas a ela associadas.

Os ensaios de Philosophy of Food, não esgotando certamente todas temáticas e matérias de reflexão filosófica em torno da função alimentar - esta condição primordial da preservação e reprodução vital do ser humano -, constitui, pela variedade e profundidade dos tópicos abordados, um importante marco bibliográfico nos estudos sobre alimentação, um contributo para nos levar "a pensar com maior clareza e responsabilidade o que comemos e bebemos, como nos sustentamos e as razões por que o fazemos." 